\title{
Pathologic complete response with radiation and vismodegib in a patient with advanced basal cell carcinoma: A case report
}

\author{
ARYA AMINI $^{1}$, MORGANNA FREEMAN $^{2}$, LALEH MELSTROM $^{3}$, KIM A. MARGOLIN $^{2}$ \\ VISHWAS PAREKH ${ }^{4}$, FARAH R. ABDULLA ${ }^{5}$ and BADRI MODI ${ }^{5}$ \\ Departments of ${ }^{1}$ Radiation Oncology, ${ }^{2}$ Medical Oncology, ${ }^{3}$ Surgery and ${ }^{4}$ Pathology; \\ ${ }^{5}$ Division of Dermatology, City of Hope National Medical Center, Duarte, CA 91010, USA
}

Received October 27, 2020; Accepted November 18, 2020

DOI: $10.3892 / \mathrm{mco} .2021 .2208$

\begin{abstract}
In locally advanced basal cell carcinoma (BCC) patients who are not surgical candidates and where radiation therapy (RT) alone would offer lower control rates, the combination of vismodegib and RT delivered concurrently may potentially improve outcomes compared to single modality treatment. The current study presents a case of very advanced, multifocal BCC who received concurrent vismodegib and RT. The patient initially came in with four large primary areas of disease including the left preauriculum, right shoulder, chest wall and right lateral ankle. All sites achieved a clinical complete response, with a pathologic complete response at the right shoulder. The ankle lesion did not require RT and continues to have a clinical complete response. The findings from our case report support several other cases with similar efficacy when vismodegib and RT are combined.
\end{abstract}

\section{Introduction}

Basal cell carcinoma (BCC) is the most common skin malignancy worldwide (1). The primary treatment for BCC includes surgical resection followed by radiation therapy (RT) if indicated based on pathologic risk factors including perineural involvement (PNI) or positive margins (2). In cases where functional and cosmetic outcomes are compromised with a surgical approach or in patients with a poor performance status, RT offers similar disease control rates in small BCCs (3). For larger tumors however, the efficacy of RT decreases, as 5-year local control rates of $95 \%$ for early stage disease decrease to $56 \%$ in advanced stages (3). Consequently, patients with advanced $\mathrm{BCC}$ who are not candidates for surgery have limited local control options.

Correspondence to: Dr Arya Amini, Department of Radiation Oncology, City of Hope National Medical Center, 1500 E. Duarte Road, Duarte, CA 91010, USA

E-mail: aamini@coh.org

Key words: vismodegib, erivedge, radiation, radiotherapy, basal cell carcinoma
Implication of the Sonic hedgehog (Shh) pathway in the development of BCC has led to the development of novel systemic Shh pathway inhibitors, providing patients with advanced BCCs new treatment options and improved survival. The primary target is through inhibition of the smoothened (SMO) protein, and both vismodegib and sonidegib are FDA approved for locally advanced or metastatic BCC (4). Vismodegib is approved for BCC patients based on data from the ERIVANCE trial, study, in which 104 patients with measurable advanced BCC received oral vismodegib $150 \mathrm{mg}$ once daily until disease progression or intolerable toxicity. The primary end point was independent review-assessed ORR (5). Objective response rates were 48 and $33 \%$ for locally advanced and metastatic $\mathrm{BCC}$, with a median response duration of 9.5 and 7.6 months, respectively (6).

In locally advanced BCC patients who are not surgical candidates and where RT alone would offer lower control rates, the combination of vismodegib and RT delivered concurrently may potentially improve outcomes. There are limited case reports on combined modality therapy, although data suggest there is a cytotoxic synergy when RT and Shh pathway inhibition are combined (7). With this in mind and in the setting of limited data, we chose to offer concurrent vismodegib and RT for a patient with very advanced, multifocal BCC.

\section{Case report}

A 65-year-old female with no prior significant history aside from a remote history of BCC removed from her scalp 20 years prior presented to our center with multiple fungating lesions that had been neglected for the past year. At the time of presentation, she had masses on the left preauricular region, right shoulder, mid-upper chest (periclavicular and parasternal), and right lateral ankle. Biopsies confirmed BCC (BER-EP4 positive), nodular type. She was evaluated by surgical oncology and not felt to be a surgical candidate due to the size and extent of her lesions, and was referred to Medical Oncology to discuss systemic therapy options. To rule out distant metastases, positron-emission tomography (PET) imaging was obtained, confirming fluorodeoxyglucose (FDG) avidity at the left preauricular lesion [standardized uptake value (SUV) 10.1; maximum dimensions of $35 \times 13 \times 42 \mathrm{~mm}$ ], right shoulder (SUV 19.7; 81x19x97 mm), upper chest wall including the 

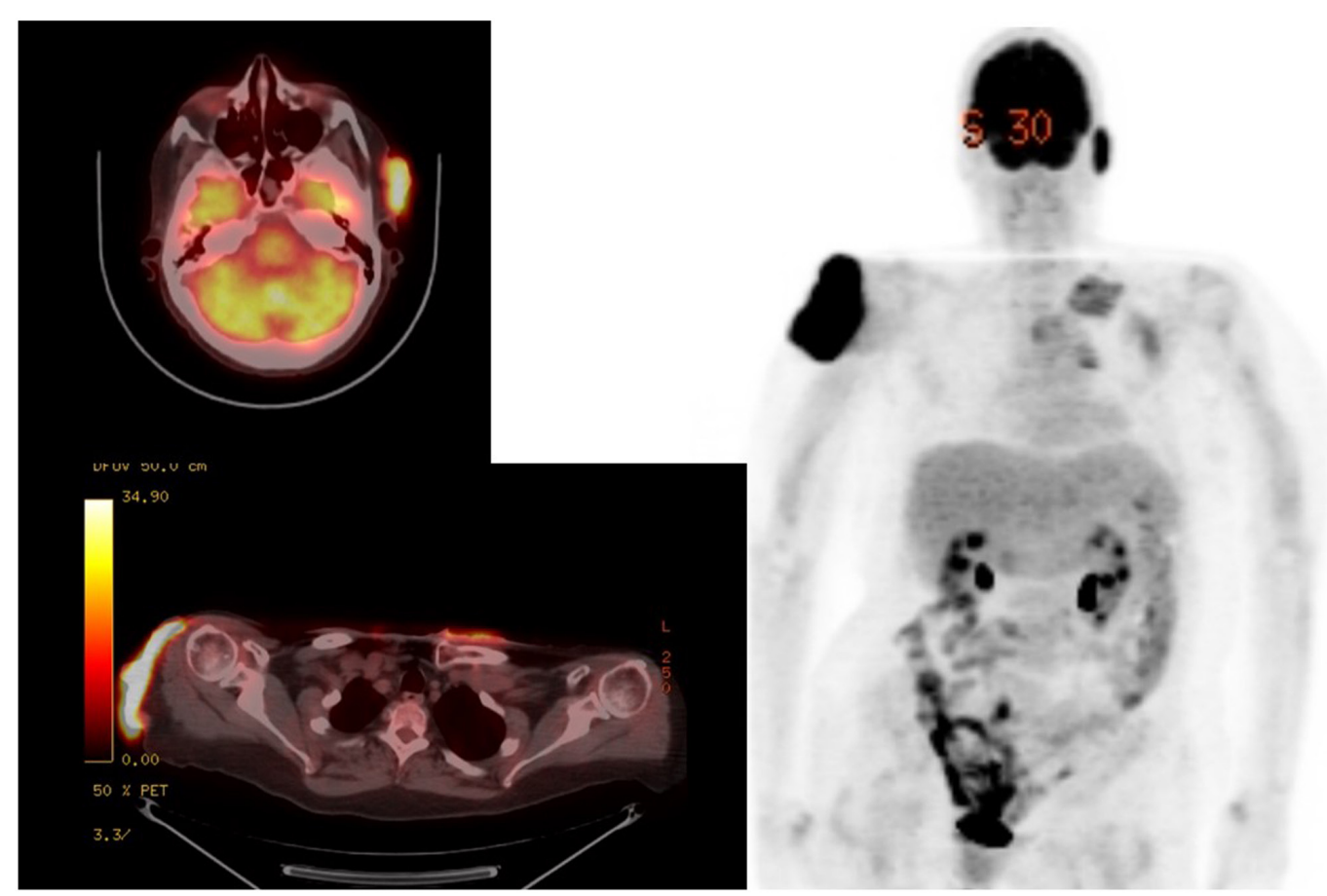

Figure 1. Positron-emission tomography scan demonstrating the left preauricular, anterior chest wall, and right shoulder basal cell carcinoma lesions.

parasternal (SUV 5.8; 66x37 $\mathrm{mm}$ ) and periclavicular regions (SUV 7.1; 65x11×39 mm), and right lateral ankle (SUV 7.1; $29 \mathrm{~mm}$ in length) (Figs. 1 and 2). Her case was discussed at our multidisciplinary skin tumor board and given the extent of her disease, the recommendation was to proceed with concurrent vismodegib $150 \mathrm{mg}$ daily and RT to each of the involved sites. RT was initially directed at the largest symptomatic areas which included the left preauricular region and the right shoulder. She received 55 Gy in 20 fractions (2.75 Gy per fraction) with electrons and was referred to Wound Care for local home health services. In addition to fatigue, she developed grade 2 desquamation at both treatment sites [Common Terminology Criteria for Adverse Events (CTCAE_v5)], which resolved within 4 weeks of RT completion. Following treatment, she continued vismodegib but required dose interruption and dose reductions due to grade 2 fatigue, grade 2 alopecia, grade 2 loss of appetite, grade 1 diarrhea, and grade 1 muscle spasms. At 6 months post-RT evaluation, she had clinically suspected residual disease at the right shoulder and the decision was made to proceed with wide local excision. Final pathology returned negative for BCC, confirming a pathologic complete response. She continued to have a clinical complete response in the left preauricular region, and similarly had a complete clinical response in the $\mathrm{R}$ lateral ankle with systemic treatment alone.

The two chest wall areas showed a suboptimal clinical response, with only a $20 \%$ reduction in size after 6 months of vismodegib, likely due to the extensive involvement of the chest. Given persistent bleeding at the site, the patient opted for consolidative RT (55 Gy in 20 fractions), which lead to a clinical complete response. Grade 3 moist desquamation was observed, and in addition to Wound Care she was referred to Pain Management due to escalating analgesic requirements. At the time of completion of RT to her chest wall (9 months from the initial start of systemic therapy), vismodegib was discontinued due to ongoing diarrhea, fatigue, muscle spasms (outside the radiation field), and persistent moist desquamation at the chest wall site.

The patient continued to be followed by the multidisciplinary team at regular clinical intervals, and her fatigue and diarrhea resolved within 3 months of drug discontinuation. At 18-month follow up, she continued to have a complete clinical response at all of her treated sites, with no further evidence of recurrence (Fig. 2).

\section{Discussion}

While surgery and RT or a combination of both are curative options for the majority of patients presenting with $\mathrm{BCC}$, in patients with advanced disease who are not surgical candidates, local therapy with RT alone results in suboptimal disease control rates. Vismodegib has demonstrated clinical efficacy in locally advanced and metastatic BCC, although the side effect profile limits how long patients can continue on therapy. In the case presented herein, we demonstrate the efficacy and tolerability of combination RT and vismodegib to treat very advanced, multifocal BCC. The patient presented with four large primary areas of disease including the left preauricular, right shoulder, chest wall, and right lateral ankle. All sites achieved a clinical complete response, with a pathologic complete response at the right shoulder. The ankle lesion did not require RT and continues to have a clinical complete response. The findings from our case report support several other cases with similar efficacy when vismodegib and RT are combined $(8,9)$.

To date, there is no evidence to suggest systemic chemotherapy improves local control outcomes when combined with RT for advanced BCC. In 2012, vismodegib became the first systemic therapy approved for BCC (5), 

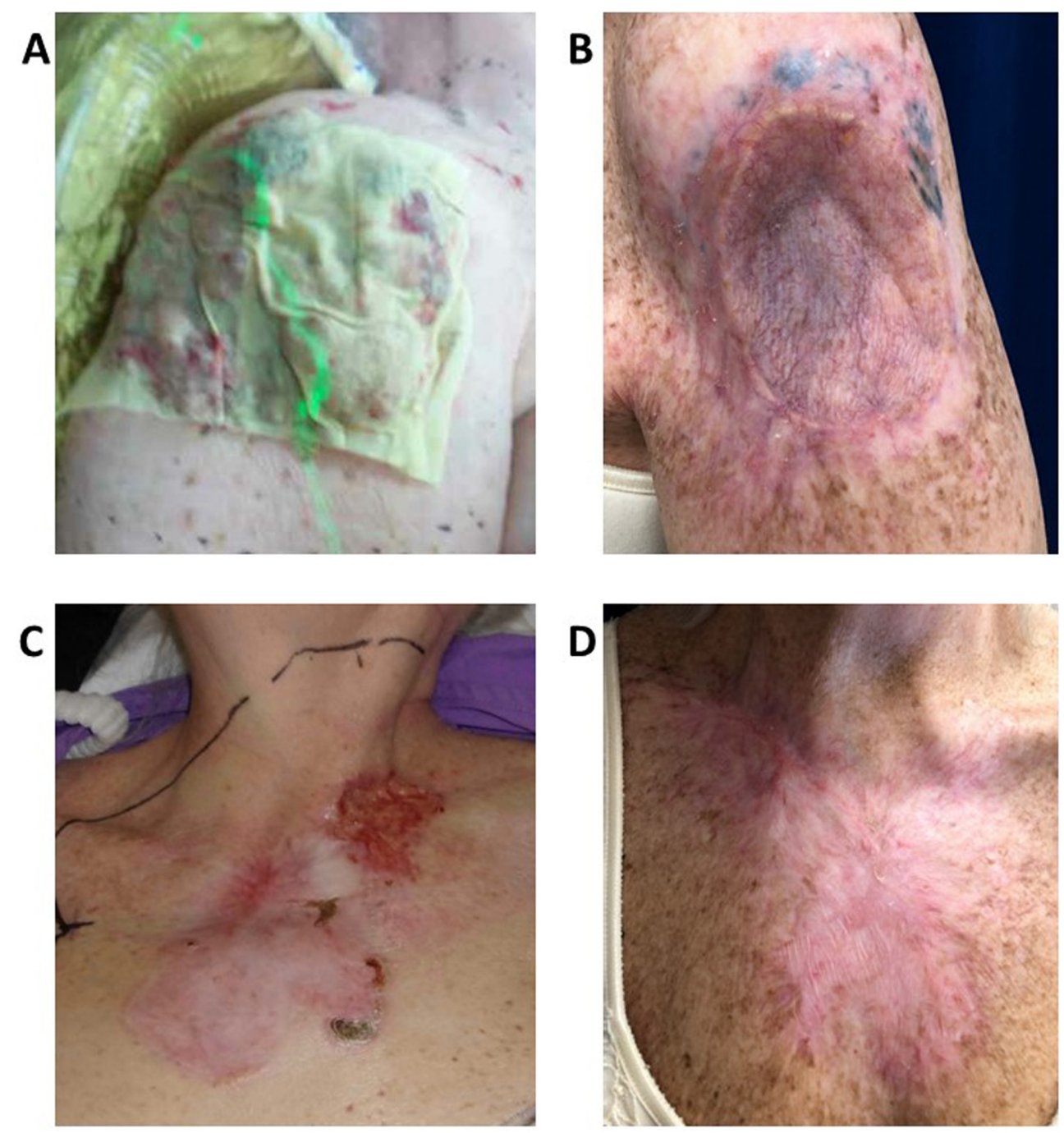

Figure 2. Physical exam findings. (A) pre- and (B) post-radiation treatment of the right shoulder BCC and (C) pre- and (D) post-radiation treatment of the chest wall BCC. BCC, basal cell carcinoma.

followed by sonidegib approval in 2015, and evidence continues to be generated as combination with RT is explored in advanced, unresectable cases $(10,11)$. In our patient with multifocal BCC, all lesions exhibited some response to vismodegib, with complete and durable responses noted in those larger lesions treated with combination therapy and a durable complete clinical response in the right lateral ankle lesion with vismodegib alone, a remarkable finding. In particular, pathologic complete response was observed in the right shoulder, where lesions measuring $>10 \mathrm{~cm}$ would normally be expected to have relatively low durable control rates with RT alone. Radiosensitization with vismodegib is supported in pre-clinical models for lung cancer and potentially appears to have similar results in BCC based on other reported series (12). Therefore, in light of knowing some BCC do not respond completely to vismodegib alone, based on clinical trial data as well as what was observed in our patient's chest wall lesion, a combination of RT and vismodegib may be an effective option for non-surgical candidates.

There is limited data on the toxicity profile of combining RT with vismodegib. Our patient was able to tolerate 9 months of vismodegib, at which point it had to be discon- tinued due to persistent side effects including fatigue, loss of appetite, alopecia, diarrhea and muscle spasms (outside the radiation field), as demonstrated in other studies (8). Of note, patients in the ERIVANCE trial (5) were on vismodegib for a median 12.9 months; this difference in duration of treatment compared to our patient may be related to the toxicity of concurrent RT. The fatigue associated with RT may be further compounded by the malaise attributed to Shh inhibitors, and, as in our case, dose interruption or reduction may be necessary to ensure continued drug adherence. Further, local side effects due to RT also appeared to be enhanced in our patient, who experienced grade 3 moist desquamation after treatment to the chest wall that persistent for 1 month following treatment before resolving. The patient required escalated analgesic therapy as well as weekly wound care visits until her local side effects improved; the delayed tissue recovery post-radiation may be explained by the fact that hedgehog signaling is essential for wound healing, and Shh interfere with this process (13).

The optimal management for multifocal, advanced BCC can be challenging and requires a multidisciplinary discussion between dermatologists, surgeons, medical oncologists, and 
radiation oncologists in order to achieve best outcomes. In our case, tri-modality therapy (systemic treatment, radiation and surgery) resulted in complete clinical and pathologic responses in multiply enlarged BCC lesions for which surgery alone would not have been curative. Additional specialty referrals to Wound Care and Pain Management should be considered for patients with bleeding, fungating, or physically deformative tumors. Future prospective trials including the ongoing phase II study combining RT and vismodegib for advanced head and neck BCC (NCT01835626) will provide insight into this combination approach (14), and further guide multidisciplinary treatment decisions for patients with advanced disease.

\section{Acknowledgements}

Not applicable.

\section{Funding}

No funding was received.

\section{Availability of data and materials}

Not applicable.

\section{Authors' contributions}

AA and BM analyzed and interpreted the patient case and reviewed the literature. VP reviewed the pathology section of the paper. AA, MF, LM, KM, FRA, VP and BM were major contributors in writing the manuscript. All authors read and approved the final manuscript.

\section{Ethics approval and consent to participate}

Consent to participate was obtained from the patient.

\section{Patient consent for publication}

Informed consent was obtained for publication of patient data.

\section{Competing interests}

Dr Amini is a paid consultant for RefleXion and is on the speaker's bureau for AstraZeneca and Takeda Oncology. Dr Modi is a paid consultant and a member of the speaker's bureau for Regeneron and Sanofi Genzyme. Dr Abdulla has grant/research support from Johnson \& Johnson, Elorac, Trillium, Sterline, MiRagen, Bioniz, Mallinkcrodt, is a consultant for Mallinkrodt and a member of the speaker's bureau for Mallinkrodt. Drs. Melstrom, Margolin, and Parekh have no competing interests.

\section{References}

1. Cameron MC, Lee E, Hibler BP, Barker CA, Mori S, Cordova M, Nehal KS and Rossi A: Basal cell carcinoma: Epidemiology; pathophysiology; clinical and histological subtypes; and disease associations. J Am Acad Dermatol 80: 303-317, 2019.

2. Likhacheva A, Awan M, Barker CA, Bhatnagar A, Bradfield L, Brady MS, Buzurovic I, Geiger JL, Parvathaneni U, Zaky S and Devlin PM: Definitive and postoperative radiation therapy for basal and squamous cell cancers of the skin: Executive summary of an American society for radiation oncology clinical practice guideline. Pract Radiat Oncol 10: 8-20, 2020.

3. Wilder RB, Kittelson JM and Shimm DS: Basal cell carcinoma treated with radiation therapy. Cancer 68: 2134-2137, 1991.

4. Armstrong P, Martin S and Lask G: Sonic hedgehog pathway inhibition in the treatment of advanced basal cell carcinoma. In: Biologic and Systemic Agents in Dermatology. Springer, Cham, pp541-548, 2018

5. Sekulic A, Migden MR, Oro AE, Dirix L, Lewis KD, Hainsworth JD, Solomon JA, Yoo S, Arron ST, Friedlander PA, et al: Efficacy and safety of vismodegib in advanced basal-cell carcinoma. N Engl J Med 366: 2171-2179, 2012.

6. Sekulic A, Migden MR, Lewis K, Hainsworth JD, Solomon JA, Yoo S, Arron ST, Friedlander PA, Marmur E, Rudin CM, et al: Pivotal ERIVANCE basal cell carcinoma (BCC) study: 12-month update of efficacy and safety of vismodegib in advanced BCC. J Am Acad Dermatol 72: 1021-1026.e8, 2015

7. Hehlgans S, Booms P, Güllülü Ô, Sader R, Rödel C, Balermpas P, Rödel F and Ghanaati S: Radiation sensitization of basal cell and head and neck squamous cell carcinoma by the hedgehog pathway inhibitor vismodegib. Int J Mol Sci 19: 2485, 2018

8. Franco AI, Eastwick G, Farah R, Heyboer M, Lee M and Aridgides P: Upfront radiotherapy with concurrent and adjuvant vismodegib is effective and well-tolerated in a patient with advanced, multifocal basal cell carcinoma. Case Rep Dermatol Med 2018: 2354146, 2018.

9. Pollom EL, Bui TT, Chang AL, Colevas AD and Hara WY: Concurrent vismodegib and radiotherapy for recurrent, advanced basal cell carcinoma. JAMA Dermatol 151: 998-1001, 2015.

10. Block AM, Alite F, Diaz AZ, Borrowdale RW, Clark JI and Choi M: Combination trimodality therapy using vismodegib for basal cell carcinoma of the face. Case Rep Oncol Med 2015: $827608,2015$.

11. Gathings RM, Orscheln CS and Huang WW: Compassionate use of vismodegib and adjuvant radiotherapy in the treatment of multiple locally advanced and inoperable basal cell carcinomas and squamous cell carcinomas of the skin. J Am Acad Dermatol 70: e88-e89, 2014.

12. Zeng J, Aziz K, Chettiar ST, Aftab BT, Armour M, Gajula R, Gandhi N, Salih T, Herman JM, Wong J, et al: Hedgehog pathway inhibition radiosensitizes non-small cell lung cancers. Int J Radiat Oncol Biol Phys 86: 143-149, 2013.

13. Le H, Kleinerman R, Lerman OZ, Brown D, Galiano R, Gurtner GC, Warren SM, Levine JP and Saadeh PB: Hedgehog signaling is essential for normal wound healing. Wound Repair Regen 16: 768-773, 2008.

14. ClinicalTrials.gov: Phase II Study of Radiation Therapy and Vismodegib for Advanced Head/Neck Basal Cell Carcinoma. ClinicalTrials.gov Identifier: NCT01835626. https://clinicaltrials. gov/ct2/show/NCT01835626. Last updated October 5, 2020

This work is licensed under a Creative Commons Attribution-NonCommercial-NoDerivatives 4.0 International (CC BY-NC-ND 4.0) License. 